\title{
Migración y movilidad académica de mujeres colombianas cualificadas, transnacionalización de los afectos y asuntos de intimidad
}

\author{
Migration and academic mobility of qualified \\ Colombian Women, trans nationalization of affects and \\ intimacy matters
}

Migração e mobilidade acadêmica de mulheres colombianas qualificadas, transnacionalização dos afetos e questões de intimidade

Carol Pavajeau Delgado ${ }^{1}$

Profesora Facultad de Psicología Pontificia Universidad Javeriana, Bogotá cpavaje@gmail.com 


\title{
Resumen
}

Este artículo pretende visibilizar los asuntos afectivos al interior de la migración y de la movilidad trasnacional femenina calificada. Se analiza desde un enfoque cualitativo el proceso de transnacionalización de los afectos a la luz de dos grupos diferentes de mujeres colombianas: el primero con siete mujeres que migraron sur-norte para conformar una unión binacional con personas del norte global. El segundo, con siete mujeres que optaron por una movilidad académica sur-sur en pareja o familia al Brasil. En ambos casos, el análisis hace énfasis en las negociaciones sobre cuestiones de afectos, dinero y carrera profesional que ellas entablan consigo mismas y con sus parejas antes y durante la migración/movilidad; también se pone especial atención a cómo estos asuntos referidos a la intimidad se interrelacionan con aspectos globales como las políticas migratorias para las primeras y las políticas científicas para las segundas. Adicionalmente, se develan importantes marcos de agencia femenina en relación con las limitaciones globales, nacionales y personales que afrontan.

Palabras clave: género; afectos; parejas binacionales; familia; migración/movilidad cualificada.

\begin{abstract}
This paper aims to make visible the affective issues within the migration and transnational mobility of qualified women. From a qualitative perspective, the process of trans-nationalization of affects is analyzed in two different groups of Colombian women: the first with seven women who migrated south-north to form a binational union with people from the global north. The second, with seven women who opted for a south-south academic mobility in a couple or family to Brazil. In both cases, the analysis emphasizes the negotiations on issues of love, money and professional career that they engage with themselves and with their partners, before and during migration/mobility; special attention is also given to how these matters related to intimacy are interrelated with global aspects, such as migration policies for the former and scientific policies for the latter. Additionally, important feminine agency frameworks are revealed in relation to the global, national and personal limitations they face.
\end{abstract}

Keywords: gender; affects; binational couples; family; qualified migration / mobility.

\section{Resumo}

O artigo visa salientar a importância dos afetos na migração e na mobilidade transnacional feminina qualificada. O processo de transnacionalização dos afetos é analisado a partir de uma perspectiva qualitativa, à luz de dois grupos diferentes de mulheres de nacionalidade colombiana: o primeiro, com sete mulheres que migraram sul-norte para formar uma união binacional com pessoas do norte global. O segundo, com sete mulheres que optaram por uma mobilidade acadêmica sul-sul em casal/família no Brasil. Em ambos os casos, a ênfase analítica são as negociações que elas fazem com elas mesmas e com seus parceiros antes e durante a migração/ mobilidade em relação a questões de afetos, dinheiro e carreira. Também se reflete em como essas questões que remitem a vida intima estão inter-relacionadas com aspectos globais como as políticas migratórias para as primeiras e as políticas científicas para as segundas. Além disso, comprovam-se importantes marcos de agencia feminina diante das limitações globais, nacionais e pessoais que elas enfrentam.

Palavras-chave: gênero; afetos; casais binacionais; família; migração/mobilidade qualificada.

¿Cómo citar este artículo? / How to quote this article?

Pavajeau-Delgado, C. Migración y movilidad académica de mujeres colombianas cualificadas, transnacionalización de los afectos y asuntos de intimidad. Sociedad y Economía, (34), 11-25. https://www.doi.org/10.25100/sye.voi34.5646 


\section{Introducción}

Dentro de los estudios migratorios los vínculos se convierten en objeto de análisis con la incursión de las miradas de género y feministas especialmente al pensar la familia y la maternidad transnacional al interior de las migraciones sur-norte (Pedone, 2008; 2011; Pedone, Romero y Gil, 2012; Echeverri, 2014; Puyana, Micolta y Palacio, 2013) y al abordar el tema de las parejas binacionales desde diferentes ángulos (Constable, 2003; 2005; Piscitelli, 2011; Riaño, 2011). Sin embargo, al interior de la migración calificada los temas de género están en proceso de visibilización (Kofman, 2000; Ackers, 2004; França y Padilla, 2017) y los asuntos vinculares y afectivos aun son poco considerados en este tipo de movilidades (Riaño, 2007; Giorgi y Raffini, 2015; Pavajeau, 2017).

Habitualmente dentro de los estudios sobre migración y movilidad calificada se adjudica como principales motivos de desplazamiento geográfico las habilidades, conocimientos y cualificación de las personas. Recientemente también a las crisis económicas y políticas de los últimos años, en los que las personas con alto nivel de cualificación tanto del sur como del norte global ven en la movilidad laboral o académica una alternativa (Pedone y Alfaro, 2015). No obstante, al aproximarse a la vida cotidiana de mujeres colombianas cualificadas que eligieron salir de su país y profundizar un poco en las diferentes situaciones que afrontaron para tomar tal decisión, cobran centralidad los asuntos afectivos $y$ vinculares.

Lo que pretendo a lo largo de este artículo es visibilizar que las cuestiones afectivas también entran en juego al tomar decisiones sobre migrar o no y describir algunas de las estrategias utilizadas por las mujeres para llevar a cabo tales proyectos. Específicamente me concentro en estudiar las relaciones amorosas y su influencia en las movilidades trasnacionales que las mujeres realizan. El eje central del trabajo es mostrar cómo emerge y se desdobla la transnacionalización de los afectos (Piscitelli, 2011) a través de las negociaciones que realizan las mujeres consigo mismas y con sus parejas en la articulación de los asuntos afectivos, económicos, laborales y/o profesionales que conllevan los proyectos migratorios y de movilidad. Para tal fin, me baso en las experiencias de dos grupos diferentes (l) mujeres colombianas cualificadas que migraron para conformar una pareja binacional con personas del norte global (2) mujeres colombianas que optaron por realizar una movilidad académica en pareja/familia al Brasil.

Con ese objetivo en el documento analizo la transnacionalización de los afectos a la luz de la interseccionalidad (Piscitelli, 2008) de género, nacionalidad, posición social, nivel de escolaridad y condiciones económicas; siendo este el caldo de cultivo que marca las condiciones de posibilidad tanto en el microescenario expresado en las negociaciones conyugales como el macroescenario manifestado en las políticas migratorias, las políticas científicas -en el caso de las mujeres académicas- y los asuntos laborales o profesionales.

En este estudio abordé a 14 mujeres colombianas cualificadas, trabajé con siete mujeres que migraron sur-norte hacia Puerto Rico ${ }^{2}$, Canadá, Francia y España y con siete mujeres que realizaron movilidad académica sur-sur para adelantar sus estudios de posgrado en Brasil. La metodología utilizada fue de corte cualitativo usando la observación participante, conversaciones informales y entrevistas semiestructuradas para recopilar las experiencias y narrativas usadas a lo largo del documento.

El artículo está dividido en cuatro partes; en la primera presento la articulación entre relaciones amorosas y movilidad femenina trasnacional cualificada. En la segunda analizo el proceso de transnacionalización de los afectos de mujeres calificadas colombianas que se unieron con personas del norte global poniendo el énfasis en la subcualificación profesional o laboral y los marcos de agencia que ejercieron en la vida íntima para afrontar tal situación. En la tercera parte me aproximo a la invisibilidad de los proyectos familiares dentro de la movilidad académica y las negociaciones íntimas e institucionales utilizadas antes y durante la

2 Ubico la migración a Puerto Rico como una migración hacia el "norte global" debido a que es un territorio no incorporado de los Estados Unidos. Pese a que existen diferencias y jerarquías claras en todos los ámbitos entre los dos países. 
movilidad para sacar adelante sus estudios de posgrado en Brasil. La cuarta y última son las conclusiones y consideraciones finales.

\section{1. ¿Cuál es la articulación entre relaciones amorosas y la migración/movilidad femenina transnacional cualificada?}

La migración/movilidad femenina transnacional cualificada en este trabajo es el contexto entre diferentes fronteras que demarca escenarios particulares donde se desenvuelven los distintos tipos de relaciones amorosas y/o sexuales. Coincido con Riaño (2007) cuando afirma que el modelo de globalización económica es muy importante para comprender la migración femenina pero es insuficiente; en su trabajo ella muestra cómo factores como "el amor" desempeñan un rol decisivo en la migración de mujeres latinoamericanas universitarias a Suiza. Destacando que es un "proceso mucho más complejo de lo que se piensa corrientemente... no es un proceso directo y obvio, sino que se compone de pasos, destinos y estrategias múltiples" (Riaño, 2007, p. 15) donde ellas son agentes activas del proyecto migratorio.

A lo largo de este trabajo se mostrarán algunas de esas complejidades y estrategias tanto en el caso de las parejas binacionales como en el caso de la movilidad académica en pareja/familia, reconociendo diferentes aspectos que buscan problematizar el concepto de migración cualificada. Se expone a través de las vivencias concretas de las mujeres lo nebuloso que es el asunto de la cualificación como categoría clasificatoria de las personas que hacen vida entre las fronteras, "creando una categoría especial para una mano de obra calificada 'deseada', en contraste con los migrantes trabajadores indeseados'. Esta clasificación ha impactado de manera clara las políticas migratorias y ha creado jerarquías y condiciones de aceptación, valoración e integración diferenciales para unos y otros" (Pavajeau, 2016, p. 1).

En este sentido, las experiencias de estas mujeres interpelan el imaginario de sujeto que envuelve tal categorización, que desconoce la diversidad de personas inmersas en este tipo de movilidad
(Bermúdez, 2014; 2015) y como consecuencia las realidades que enfrentan a pesar de ser cualificadas. La mujeres que participaron de este estudio interpelan la linealidad con la que es pensado en ocasiones este tipo de movilidad o migración y los supuestos del imaginario común sobre las personas calificadas como personajes "exitosos" con amplio nivel de circulación por el mundo por motivos laborales o académicos, con un elevado capital social y cultural que les abre las puertas a través de las fronteras.

\section{La transnacionalización de los afectos y la subcualificación profesional. Negociaciones conyugales, profesión y dinero en mujeres que migraron al norte global por "amor"}

Marina tiene 30 años. Se conoció con Lucie, su novia de nacionalidad francesa, en Bogotá. Relata que migró por "amor", ya que cuando conoció a su novia estaba pasando por un buen momento laboral y personal y no estaba en sus planes a corto plazo vivir fuera de Colombia y "mucho menos en Francia".

En la actualidad viven juntas en Paris en un pequeño y agradable apartaestudio en el barrio 18. Marina es enfática en manifestar que no depende económicamente ni por papeles de su chica, especialmente con la familia de su novia ya que en ocasiones se ha mostrado inquieta porque Lucie ande con una mujer extranjera. ¿Cuáles son las preocupaciones de la familia de Lucie? No es en sí por Marina, en realidad ella les agrada, es todo lo que conlleva vivir con una "mujer del tercer mundo"3. Por fortuna Marina tiene nacionalidad italiana, así que no tiene dificultades por papeles; su mayor desafío ha sido ubicarse laboralmente, es politóloga y al ver disminuidos sus ahorros, el primer año que

3 Quiero hacer uso de este termino aproximándome a la mirada crítica que plantea el feminismo poscolonial donde autoras como Chandra Mohanty (1984) e Avthar Brah (2006) señalan lo conflictivo del término "mujeres del tercer mundo" por la jerarquía que producen entre países y los imaginarios que estos generan en específico sobre las mujeres del sur global que cruzan las fronteras por diversos motivos. 
llegó incursionó en el trabajo informal: limpiando casas vacacionales, creando su propio emprendimiento de ventas de empanadas colombianas en París que funciona sobre todo haciendo catering y participando en festivales en la ciudad, eventos que según ella la "desvaran" bastante, pero los mayores ingresos los obtiene viajando dos o tres veces al año a California para trabajar en la recolección de cosecha de marihuana que le permite reunir una cantidad importante de dinero para vivir en París mientras resuelve su situación laboral en este país (Notas diario de campo).

La experiencia de Marina y de otras mujeres colombianas que componen este apartado muestra la complejidad de su trayectoria migratoria al integrar sus experiencias laborales con las afectivas, que interpelan los supuestos sobre la migración cualificada y muestran nuevos matices sobre los imaginarios de las parejas binacionales sur-norte.

Lo primero que las historias de las mujeres evidencian es que la cualificación por si misma no abre las puertas a través de las fronteras debido a que al momento de intentar ubicarse laboralmente en un país del norte global por encima de la cualificación se encuentra el lugar geopolítico de procedencia y donde realizaron los estudios tal como lo describe Carla, quien migró a Canadá en el 2013.

\footnotetext{
La primera discriminación que uno siente cuando llega a un país como estos es que nada de lo que uno haya hecho a nivel laboral en su país vale ¿Qué puede ser más discriminador que le digan a uno que nada de lo que usted ha hecho en su vida vale? Porque usted no estudió aquí, no tiene la experiencia de aquí; en conclusión no valgo nada (entrevista a Carla)
}

Carla es historiadora y escritora con una estimulante trayectoria profesional en Colombia, migró por "amor" como ella misma dice; luego de comprobar que no podía ejercer con su diploma de Colombia, decidió estudiar licenciatura. Mónica es comunicadora social, trabaja como profesora de español en Francia. Artemisa optó por realizar una carrera técnica en Francia ya que sus estudios en el área de la salud no son válidos en ese país, actualmente trabaja como auxiliar administrativa en un organismo regional. Raquel es arquitecta y trabaja como dibujante en Francia, ella misma describe la complejidad de su situación:

\begin{abstract}
Ese es un gran problema que yo tengo aquí y es que mi diploma es colombiano, no está reconocido acá; aquí te proponen hacer una formación profesional para hacer la homologación. Es pesadísimo, tienes que desplazarte a otra ciudad todos los viernes y un sábado cada 15 días durante 1 o 4 años, dependiendo de lo que exijan convalidar (Entrevista a Raquel).
\end{abstract}

Prácticamente, le implica volver a hacer la carrera de arquitecta, lo que genera a Raquel y a varias de mis interlocutoras una gran indignación y frustración. Médicas, filósofas, historiadoras, politólogas, optómetras, comunicadoras, administradoras, ingenieras, en fin, he conocido a varias mujeres profesionales que finalmente optan por subcualificarse para continuar trabajando en su área o que realizan estudios técnicos intermedios como una salida práctica para ganarse la vida. Raquel optó por subcualificarse:

\begin{abstract}
Yo no sé cómo presentarme, yo soy dibujante pero con las capacidades de arquitecta, entonces cuando postulo a dibujante me dicen que me voy a aburrir dibujando y cuando postulo como arquitecta me dicen que no tengo el diploma de arquitecta, entonces es muy complicado (entrevista a Raquel).
\end{abstract}

Carla decidió no continuar con sus estudios de posgraduación en Canadá porque le implicaba sacar un crédito demasiado costoso que al terminar después de 7 años como mínimo tendría que comenzar a trabajar para pagarlo. En Colombia ella trabajó con su titulo de historiadora como profesora en un colegio privado de la ciudad. En Canadá retomar ese camino le exigía hacer una licenciatura.

\footnotetext{
Entonces, ok, a mí lo que me gusta es trabajar con niños. Finalmente, decidí hacer la licenciatura porque eso me permite comenzar a trabajar pronto; pero claro, también me obliga a reestructurar una cantidad de cosas, como es que uno después de obtener un pregrado en vez de ir de para arriba, va para abajo (entrevista a Carla).
}

En el tránsito de volver a ubicarse laboralmente, algunas dependen económicamente de sus parejas y otras trabajan en labores informales 
generalmente cubriendo labores reproductivas para terceros. Todas coinciden en que los primeros meses o años son los más difíciles, mientras comprueban que su nivel de cualificación no tiene validez y comienzan a experimentar las diferencias y desigualdades que genera ser colombiana y tener título profesional de un país del sur y la burla de los imaginarios del desarrollo: para estas mujeres optar por irse a vivir a un país del norte global no se refleja inmediatamente ni en su carrera profesional, ni en su situación social. Una serie de factores entran en escena para que paulatinamente ellas se vayan ubicando y gestando la vida en otras fronteras, lo que invita a un análisis más complejo de relaciones amorosas, trayectoria laboral o profesional, nacionalidad, capital económico, social y cultural y movilidad social en las migraciones cualificadas femeninas.

Una de las primeras tensiones que estas mujeres experimentan es verse enfrentadas a una disyuntiva que creían superada para mujeres de su edad entre 30 y 40 años, elegir entre una pareja y su carrera profesional. Disyuntiva que en su contexto particular en Colombia no tendría que afrontar, como sí lo hicieron mujeres de generaciones pasadas. Por supuesto como consecuencia de decisiones personales de ellas, sin duda, pero dentro de un contexto geopolítico más amplio y complejo que en este caso impacta las decisiones personales de las mujeres que migran y las negociaciones de la intimidad que ellas entablan en ese proyecto migratorio con sus parejas del norte global.

En este orden de ideas, se va clarificando que las experiencias de transnacionalización de los afectos de estas mujeres con personas del norte global implican para gran parte de ellas, por lo menos inicialmente, su subcualificación profesional por ser mujeres del sur global con títulos profesionales colombianos. Frente a esta compleja situación algunas de estas mujeres ejercen su agencia (Strathern, 2006) en el ámbito de la intimidad, haciendo explicitas las implicaciones que las diferencias y desigualdades del proyecto migratorio están generando en sus vidas e intentando propiciar acuerdos con sus parejas que les permitan lidiar con estas decisiones de maneras más llevaderas. Por ejemplo algunas acuerdan no tocar sus ahorros personales para los gastos comunes, otras negocian una mensualidad que les permita contar con recursos propios mientras se ubican laboralmente, otras dejan por sentado que no van a generar ingresos debido a que tienen que volver a estudiar.

\begin{abstract}
Sin embargo, estar estudiando significa no producir un peso o sea dos años más de: esposo, yo quiero eso; esposo, me das para lo otro. Afortunadamente, mi cuenta de Colombia donde yo tenía mis ahorros nunca ha sido parte de este matrimonio; digamos que durante esos tres años me mantuvo viva esa cuenta; que quiero comprarme algo, comer algo, que no quiero pedirle a Leonardo, ahí yo he sacado de esa cuenta. Él no la toca, no tiene nada que ver con él, esa es solo mi cuenta (entrevista a Carla, quien migró a Canadá en 2013).
\end{abstract}

\begin{abstract}
Necesito que tengas muy claro qué va a pasar en lo económico, yo no voy a poder ayudarte en la casa y los gastos van a ser tu responsabilidad y mis ingresos van a ser mis ingresos porque yo necesito un mínimo de independencia económica, yo no te estoy diciendo que esto va a ser así toda la vida pero no es fácil al comienzo y dime si lo puedes asumir, si te sientes cómodo haciéndolo o ¿ cómo es para ti? Porque si no, podemos buscar otras soluciones y mientras tanto yo puedo estar yendo y viniendo y me quedo en Colombia donde tengo toda mi estabilidad..." (entrevista a Inti, quien migró a Puerto Rico en 2016).
\end{abstract}

Lo que pretendo visibilizar es la heterogeneidad, la especificidad y complejidad con que se van tejiendo estas relaciones trasnacionales para mujeres con estabilidad laboral y económica en Colombia donde adicional a los afectos son centrales los intercambios, ya que aquí el dinero, no solo representa capacidad adquisitiva y de consumo, sino una estrategia por medio de la cual ellas visibilizan sus condiciones diferenciales y negocian su relación con sus parejas. En otras palabras las personas incluyen dentro de lo que constituye una relación amorosa los recursos sociales, materiales y simbólicos con los que cuenta, recursos que Piscitelli (2011) llama de ayuda y Zelizer (2013) de vidas conectadas. Ayuda en el contexto migratorio "remite a la obtención de diversos recursos necesarios para la inserción en esos contextos y para facilitar las interacciones con las redes de 
parentesco"4 (Piscitelli, 2011, p. 567), tanto en destino como en origen. Por su parte, vidas conectadas se refiere a la manera en que las actividades económicas se mezclan con los asuntos de intimidad que se expresan en la forma como las personas "utilizan las actividades económicas incluso el dinero para crear, diferenciar, sustentar y renegociar vínculos importantes, en especial lazos de intimidad con otras personas" (Zelizer, 2013, p. 97).

Basándome en los planteamientos de estas autoras, considero que dentro de las relaciones conyugales, amorosas/sexuales las transacciones económicas ocupan un lugar central. Aun es fuerte el legado de las esferas separadas donde el dinero o asuntos materiales contaminan el amor y lo transforman en un amor interesado, ese es un legado del amor romántico que sigue generando contradicciones en las narrativas y prácticas de mis interlocutoras. Sin embargo, también observé que los arreglos entre las parejas no se sustentaron ni en la negación de la contradicción, ni en la simple mercantilización de la vida; es en ese punto unas veces más allá, otra más acá, que en ocasiones generó fricciones y malestares pero que al hacerlo explícito facilitó y promovió la continuidad de la relación, la consolidación del proyecto migratorio y la posterior convivencia, siendo generalmente un aspecto neurálgico en las experiencias amorosas de estas mujeres.

Por contraste, hay otras mujeres que ante la disyuntiva de elegir entre su carrera profesional o un amor del norte global, eligen la primera. Amanda, una profesora colombiana que conocí en un congreso internacional en Brasil, luego de escuchar mi ponencia realizó una intervención donde relató un fragmento de su historia. Ella es una mujer alta de piel canela, ojos y cabellos negros, su puesta en escena expresa seguridad y fuerza, tanto con su voz como con su cuerpo, comienza mencionando que mi trabajo le recuerda su propia experiencia años atrás cuando ella viajó a Europa con el objetivo de realizar su formación de posgrado e hizo una primera maestría en Suecia y otra en España, donde también continuó con sus estudios doctorales; allí consiguió un novio español, estuvo dos años

4 Traducción libre. decidiendo si se quedaba en España o se regresaba para Colombia. Para ella es muy importante su carrera profesional y tenía el problema que a pesar de ser formada por una universidad española había comprobado que no tenía el mismo estatus y posibilidades de desarrollo profesional que las personas oriundas de España. Finalmente decidió regresar a Colombia y continuar con su carrera académica.

\begin{abstract}
Mi problema no es que me formé en España, mi problema era que estando allá era colombiana. Finalmente, yo preferí ser una académica en América que una mujer casada en Europa. ¿Cómo yo, siendo una mujer autónoma económicamente, con autoridad profesional, hago una transitividad a ser una mujer dependiente, sospechosa, a negociarlo todo? ¿Paso de tener una voz de autoridad sobre mi vida a tener una voz en negociación permanente? Esa transitividad era muy amorfa para mí, lo que representaba antes de venirme, lo que soy aquí en un estado de idealización amorosa. Yo le estoy entregando mi autonomía económica, mi estatus, de una forma u otra me estoy resignificando y ¿qué tipo de representación tengo yo dentro de ese marco? ¿Realmente qué estoy yo intercambiando a pesar de esa deslocalización tan costosa? ¿Qué costo tiene para la vida de las mujeres ese poder del amor?, ¿ ${ }_{¿}$ Hasta dónde aguanta? A mí no me aguanto mucho (notas diario de campo).
\end{abstract}

Amanda cuestiona lo costoso que es para una mujer profesional con independencia económica en su país optar por una unión trasnacional con una persona del norte global. Carla, Artemisa, Inti, Raquel y Marina también lo reconocen, lo explicitan, les incomoda y buscan maneras de hacerlo llevadero.

Ahora quisiera proponer el ejercicio inverso, ampliar el panorama de la decisión personal de las mujeres y el nivel relacional de las negociaciones con las personas del norte global con quienes entablan una relación amorosa. Lo anterior para visibilizar el impacto de la geopolítica en las fronteras, que crea no solo políticas públicas migratorias que restringen tanto la movilidad como la posibilidad del ejercicio profesional requerido en el caso de estas mujeres del sur para hacer una vida a través de las fronteras y ampliar sus marcos de actuación público-privados en el norte global, sino también 
que promueve imaginarios sociales sobre las mujeres del "tercer mundo", las mujeres "latinas" que las encasilla, al punto de generar mecanismos de hipervigilancia y control jurídicos y sociales sobre las uniones trasnacionales. Estas miradas lineales y homogéneas que encajan a las mujeres del sur global como "mujeres producto del subdesarrollo" reducen el marco comprensivo de las relaciones amorosas y el matrimonio en contextos migratorios y desconoce la diversidad de motivos, trayectorias y experiencias de las personas envueltas en los relacionamientos afectivos y sexuales transnacionales.

\section{Transnacionalización de los afectos y políticas científicas e institucionales: mujeres que cruzaron las fronteras sur-sur por motivos académicos con sus parejas/familia 5}

Este apartado focaliza la relación entre migración calificada, políticas científicas e institucionales y relaciones de la intimidad, por medio de las trayectorias afectivas y de movilidad académica de mujeres colombianas que se trasladaron en pareja/familia al Brasil para hacer sus estudios de posgrado en diferentes áreas (ingenierías, artes, ciencias sociales, antropología, economía, demografía, física).

Es un hecho que al interior de los proyectos de movilidad académica además de estudiar, las personas se enamoran, se separan, crean relaciones amorosas abiertas o cerradas en la distancia, algunas optan por tener descendencia, otras por interrumpir embarazos, otras viajan en pareja o en familia y esta mezcla de intereses hace que se generen diversas

5 Parte de este trabajo fue presentado a modo de ponencia y se encuentra en las memorias del seminario internacional Researchers crossing borders: transnational scientific mobility, Universidade Nova de Lisboa, Portugal, septiembre de 2015 y en el Primer Seminario internacional sobre migraciones cualificadas en América Latina. Retos y Perspectivas", Pontificia Universidad Javeriana, Bogotá, Colombia, septiembre de 2016. estrategias y arreglos para que las vidas fluyan. Sin embargo, específicamente en este tipo de movilidad pocas veces se perciben como importantes las vinculaciones afectivas que tienen las personas y las maneras en que se las arreglan para sostener estos mundos aparentemente separados en los escenarios públicos pero necesariamente articulados en la vida cotidiana de la mayoría de las personas del común (Pavajeau, 2017).

Dentro de los estudios migratorios en Colombia son recurrentes los temas relacionados con los vínculos y los asuntos familiares ${ }^{6}$; sin embargo, dentro de los estudios sobre movilidad académica es una cuestión invisibilizada. No se tiene en cuenta a las parejas e hijos/as de las personas que hacen parte de la movilidad académica al definir su población de estudio. Tampoco se han interesado en comprender lo que se gesta en los escenarios micros de la vida cotidiana de estos sujetos, ni el impacto que las políticas científicas e institucionales tienen en los procesos de toma de decisiones personales, conyugales y profesionales que este tipo de movilidad demanda.

El supuesto comúnmente generalizado del carácter individual para la totalidad de proyectos de movilidad académica en las políticas migratorias y científicas y, por ende, en el medio académico ha tenido implicaciones de diferentes niveles para las mujeres participantes de este estudio, que va desde las gestiones migratorias, las estrategias para conseguir migrar en pareja/familia, hasta el uso que hacen de las transacciones económicas y el trabajo relacional para generar, sostener o transformar sus vínculos (Zelizer, 2009). Las becas que ofrece el gobierno brasilero y los créditos

6 En Colombia es un tema investigativo en ascenso con trabajos como los de Puyana, Motoa y Viviel (2009) y Rivas y Gonzálvez (2009) sobre familiares transnacionales y género; Echeverry (2010; 2014) que destaca el lugar de los jóvenes como actores sociales de las dinámicas familiares en contextos migratorios; Gil y Pedone (2014) abordan las políticas públicas y discursos políticos sobre familia, migración y género en contextos de inmigración/emigración; Gonzálvez (2010), Puyana et al. (2013) le dan centralidad al tema de los cuidados. 
condonables ${ }^{7}$ que ofrece el gobierno colombiano son individuales, no familiares; si la estudiante viaja acompañada por su pareja e hijos/as al dirigirse a la embajada de Brasil en Colombia para realizar los trámites de las visas, debe demostrar que tiene los recursos económicos suficientes para sostener a sus acompañantes a través de un documento legalizado en notaría pública donde certifique que su pareja e hijos/as son personas a su cargo. Este documento también puede ser emitido por un familiar que se quede en Colombia y que certifique que es la persona encargada del sostenimiento de la persona acompañante durante su estadía en Brasil. Tal fue el caso de Camila quien hace el doctorado en física en este país.

Mi mamá me hizo el favor de darme el certificado de sostenimiento que nos pedían en la embajada para poder obtener la visa de nuestros hijos, a pesar de que para todos era claro que con el dinero de las becas de nosotros dos nos íbamos a sostener los cuatro (entrevista a Camila).

Algo que sorprendió a Camila posteriormente cuando fue a recoger los pasaportes fue darse cuenta de que sus hijos tenían visa de estudiante, vinculados al colegio que iban a ingresar en Brasil. Los dos nos preguntamos ¿La embajada los registró como familia o como estudiantes vinculados a las instituciones educativas de manera individual? Otra manera más sencilla que las personas colombianas han encontrado para obtener las visas es a través del convenio Mercosur donde se otorga un

7 Para disminuir las tasas de no retorno de la población con formación altamente calificada Colciencias financia los estudios doctorales a través de créditos condonables. Según la convocatoria 2014, la condonación consiste en eximir al beneficiario/a hasta el $100 \%$ de la deuda adquirida mediante el siguiente procedimiento: (1) Culminación del programa de doctorado y obtención del título correspondiente (2) Retornar a Colombia, dentro de los 30 días siguientes a la culminación del programa doctoral. (3) Permanecer en el país vinculado a una entidad del Sistema Ciencia y Tecnología por un periodo mínimo de 2 años, realizando actividades cualificadas de ciencia tecnología e innovación -CTI-. A pesar de que los criterios y rubros de cada convocatoria pueden cambiar anualmente, se puede decir que Colciencias financia por 4 años, matrícula (en caso de requerirla), seguro médico, sostenimiento mensual fijo (sin incremento anual) y tiquetes aéreos por una sola vez. permiso temporal de residencia por dos años a los ciudadanos que tengan nacionalidad de los países que hacen parte del convenio, dentro de los que se encuentra Colombia como país invitado.

Lo importante aquí es visibilizar que no en pocas oportunidades existe una distancia enorme entre las políticas y la realidad concreta de las personas. Mientras las políticas científicas en Colombia no perciban que un grupo importante de sus ciudadanos que se acogen a sus programas de cualificación profesional tienen vínculos familiares que habría que contemplar, las personas seguirán buscando estrategias para sacar adelante simultáneamente sus proyectos afectivos y sus proyectos profesionales. Este es uno de los motivos principales por el que mis interlocutoras escogieron Brasil, básicamente porque está en el sur y eso significa que el dinero que ellas obtengan de sus becas puede generar mayor rendimiento que en un país del norte y podría permitirles trasladarse con los suyos, pero por otro lado, y no menos importante porque un numero significativo de universidades brasileras son reconocidas por su destacado nivel académico.

\footnotetext{
Yo soy separada, tengo la custodia de mi hija de 13 años y quería doctorarme para avanzar en mi carrera académica. Necesitaba encontrar un lugar que cumpliera mis expectativas académicas y que también me permitiera irme con mi hija, un lugar que fuera chévere para ella también y que alcanzara el dinero para vivir modestamente las dos (entrevista a Patricia).
}

En el intento de poder articular familia-estudio, las mujeres analizaron con detenimiento los asuntos económicos, buscando formas de sostenimiento que a pesar de ser concebidas por las instituciones como individuales, fueran viables para el sostenimiento de la familia al articularlas con el costo de vida del país y la ciudad. En una conversación informal una colombiana estudiante del doctorado en ingeniería me comentó:

Varios amigos que habían llegado de hacer el doctorado me decían: piénselo bien, haga cuentas, hay países con doctorados muy buenos en Europa y Estados Unidos pero con unos costos de vida altísimos para 
nosotros los colombianos, a varios les toca buscarse trabajos adicionales por allá o endeudarse más (notas diario de campo).

Comúnmente el binomio familia-doctorado es concebido en el mundo académico como incompatible, especialmente cuando se prefiere realizar un posgrado en el exterior. Este grupo de mujeres ha optado por no elegir entre su formación profesional y sus vínculos. Ahora bien, es interesante observar que no todos los migrantes calificados tienen tal presión; por ejemplo, en los proyectos migratorios de personas altamente calificadas acogidos a un programa de recepción de un país o los asociados a redes empresariales es común encontrar que estos programas contemplan la movilidad familiar a corto o mediano plazo. Es evidente que estas diferencias entre los tipos de grupos de migrantes calificados presentan como telón de fondo los diversos intereses políticos y económicos que los moviliza, aspecto que no pretendo desarrollar en este documento, pero que expongo para dimensionar la complejidad del macroescenario.

La invisibilidad de los proyectos migratorios familiares dentro de la movilidad académica de larga duración, lleva a preguntarse cuál es el lugar que ocupan los afectos y los vínculos en las políticas de movilidad académica. ¿Cómo ubicar los afectos dentro del imaginario del sujeto que en las políticas científicas denominan "capital humano altamente calificado"? ¿Cuáles son los marcadores sociales de diferencia que están en la base de estas políticas? ¿Cuáles son los perfiles en clave de género, generación y clase que son privilegiados? En últimas, ¿cuál es el sujeto que está en la base de estas políticas?

\subsection{Políticas científicas y afectos: negociando afectos, dinero y carrera profesional}

Las políticas científicas del gobierno colombiano y las políticas institucionales en las universidades generan las condiciones de posibilidad de movilidad académicas de personas colombianas en diferentes ámbitos. Analizando concretamente lo concerniente a la beca y a la carrera profesional entran a viabilizar o limitar, presionar o facilitar los procesos de movilidad trasnacional de algunas personas que no desean emprender solas la movilidad académica de larga duración, ni elegir entre sus proyectos familiar y profesional. Es en este tipo de elecciones donde entran en escena los afectos. Intentando comprender estas relaciones entre lo macro y lo micro, me voy a centrar en las negociaciones entre dinero, afectos y carrera profesional que mis interlocutoras realizaron con sus parejas para conseguir trasladarse juntos en un proyecto de movilidad visto institucionalmente como individual y adicionalmente las decisiones estratégicas que están utilizando para sostener los vínculos que envuelven asuntos económicos. Hay un sin número de elementos en juego que están detrás de estos proyectos de movilidad, donde se mezclan intereses personales, profesionales y familiares; lo que demanda un intenso trabajo en las relaciones para tomar decisiones estratégicas que permitan sacar adelante la idea de hacer un doctorado con la pareja/familia. Las parejas y mujeres que entrevisté planearon por años este viaje. Un primer elemento donde se articulan afectos con carrera profesional fue negociar el momento vital indicado, académica y laboralmente para cada uno como lo expresa Alana:

\footnotetext{
No teníamos el mismo ritmo, no coincidíamos frente al momento en que queríamos hacerlo. Yo empecé mucho tiempo antes con la idea de hacer el doctorado, ya había hecho la maestría y tenía presión en la universidad para comenzar con el doctorado. Yo era la única profesora de planta solo con maestría, yo no sé por qué a mí me dejaron entrar solo con la maestría, yo fui la última, de resto todos tienen doctorado, entonces había presión bastante fuerte que se refleja en la imposibilidad de ascenso salarial y además comenzaron a ponerme límites para poder investigar, yo no podía presentar una propuesta de investigación sola, entonces me tocó asociarme a veces con otros colegas que no necesariamente iban en la misma línea mía y perdía la autonomía en términos investigativos (entrevista a Alana).
}

Lo que está en la base de la situación expuesta por Alana es la articulación de una presión laboral para obtener su título doctoral sin condiciones de 
Migración y movilidad académica de mujeres colombianas cualificadas, transnacionalización de los afectos y asuntos de intimidad

posibilidad para realizar la movilidad académica en pareja/familia, situación expuesta por varias de las mujeres participantes que tenían vínculos laborales con universidades colombianas o que aspiran a realizar carrera académica. Lo que inicialmente podría pensarse como decisiones del ámbito de las relaciones íntimas comienza a mostrar nuevos matices cuando se visibilizan presiones como: límite de edad para solicitar apoyo de estudios, imposibilidad de ascenso o condicionamientos en sus labores investigativas existentes.

Es así como se va haciendo cada vez más clara la relación entre afectos, carrera profesional y políticas institucionales o científicas, al evidenciarse las tensiones que las políticas van generando en las personas para sostener y avanzar en su carrera profesional; sin tener en cuenta los proyectos afectivos y familiares que estas personas tienen y que optan por intentar conciliar, en contravía de los beneficios planteados por las políticas, por ser pensados en términos exclusivamente individuales como por ejemplo, no permitir adquirir un plan de salud familiar.

\begin{abstract}
Escribí al operador administrativo de Colciencias para explorar la posibilidad de adquirir un plan de salud familiar que no excediera el valor que ellos me adjudicaron para mi seguro personal y mira el e-mail con la respuesta: "El seguro médico es beneficio exclusivo al estudiante. Sin embargo, si decide adquirir un seguro familiar, Colciencias sólo asumiría la porción individual, teniendo que asumir la diferencia el mismo beneficiario (entrevista a Laura).
\end{abstract}

Los argumentos jurídicos y administrativos de la negación son claros; lo que existe es una pugna constante entre las necesidades de las personas y las debilidades de las políticas. Esto se agudiza con la ausencia de licencia remunerada de maternidad para una mujer que queda embarazada mientras realiza sus estudios doctorales; al respecto lo que se nombra en los términos de referencia es la opción de la suspensión temporal del desembolso por 6 o 12 meses según el reglamento tanto de doctorados en el exterior como nacionales de Colciencias ${ }^{8}$. Cir-

8 http://www.colciencias.gov.co/sites/default/files/ reglamento-operativo-.pdf cunstancia que pone a las mujeres en situaciones desfavorables cuando optan por embarazarse.

Lo pensamos mucho, pero nos decidimos porque estoy en el límite de edad para poder embarazarme; ahora estamos decidiendo qué vamos a hacer con el asunto del dinero, porque ¿tú sabes lo que es suspender el desembolso justo ahora con la llegada de un bebé? Pero, por otro lado, si no lo hago me toca correr para terminar el doctorado, no voy a poder tener un tiempo de licencia de maternidad tranquila, es como si no tuviera derecho por las condiciones que plantea Colciencias de ser buena mamá y buena científica (entrevista a Lorena).

Es claro que el crédito condonable de Colciencias no es un contrato laboral, y este es el argumento jurídico que justifica la no remuneración de la licencia de maternidad de sus beneficiarias; sin embargo, una vez más la norma está distante de las realidades de las mujeres. Condiciones de posibilidad como estas fueron ganadas años atrás gracias al feminismo; varias de las becas de otros países -incluyendo la del gobierno brasilero- contempla como derecho la licencia de maternidad remunerada para sus estudiantes, pero Colombia no.

Seguro de salud, tiquetes, trámites migratorios, gastos de instalación, de sostenimiento y demás asuntos económicos también entran dentro de las negociaciones estratégicas que las mujeres hacen con sus parejas y con las condiciones de posibilidad económica que brindan las políticas para generar, sostener o transformar sus vínculos en el intento de sacar adelante un proyecto de movilidad académica de larga duración. En estas parejas se evidencian los usos estratégicos que las personas están realizando de las transacciones económicas que las becas y créditos de los dos países les ofrece para conseguir articular familia-estudio. Lo preocupante es la cantidad de deudas adquiridas con las entidades colombianas públicas y privadas encargadas de regular, administrar y ejecutar las políticas científicas para poder sacar adelante la carrera académica, lo cual adicionalmente genera diversas inquietudes con respecto al retorno y a las estrategias utilizadas por las políticas científicas colombinas para 
retener su capital humano altamente calificado, como se evidencia a continuación:

Luna se gana la beca PEC-PG para hacer la maestría en Brasil, y Lorenzo obtiene el cupo en un doctorado en la misma universidad. Él es profesor de planta en una universidad privada en Bogotá y tiene presión institucional por el límite de edad para iniciar sus estudios doctorales, así que decide adquirir dos créditos, uno con Colfuturo ${ }^{9}$ parcialmente condonable y otro con la universidad para la que trabaja totalmente condonable. Luego de dos años la financiación se acaba y él obtiene una beca FAPESP (Fundação de Amparo à Pesquisa do Estado de São Paulo $)^{10}$ hasta finalizar el doctorado. Luego de tres años Luna terminó sus estudios de maestría, y decide continuar con el doctorado, esta vez financiado por Colfuturo los primeros dos años; a partir del tercero consigue el crédito beca con Colciencias que va hasta finalizar los estudios (notas diario de campo).

La condonación de las deudas está sujeta al retorno, en donde también entran en juego los afectos; así como intentaron hacer coincidir todas las piezas para migrar juntos, ahora hay que hacer la gestión para volver juntos, lo que ha exigido a parejas como Luna y Lorenzo no solo una intensa negociación entre ellos, sino

9 Colfuturo es una entidad colombiana privada que trabaja con fondos mixtos público-privados financiando estudios de posgrado en el exterior. Los estudiantes pueden solicitar hasta US\$25.000 por año, máximo por dos años; es decir, hasta un tope de US\$50.000. Es un préstamo en dólares americanos que requiere dos codeudores. Si el estudiante regresa a Colombia en el tiempo establecido después de obtener el título que Colfuturo le ayudó a financiar y permanece en el país de 3 a 5 años, podrá obtener el $50 \%$ de condonación sobre el monto desembolsado y $10 \%$ adicional si el beneficiario se vincula laboralmente, durante un año de tiempo completo, a una entidad pública, académica o de investigación. El excedente del crédito debe pagarlo en dólares. http://www.colfuturo.org/financiacion-para-posgrados-en-el-exterior\#sthash.21GhiORH.dpuf

10 Fundação de Amparo à Pesquisa do Estado de São Paulo es una de las principales agencias de fomento a la investigación científica y tecnológica del Brasil. La FAPESP apoya la investigación o el intercambio y la divulgación de la ciencia y la tecnología producida en São Paulo. http://www.fapesp.br/ con las instituciones con las que adquirieron los créditos condonables:

\footnotetext{
Luna está en su segundo año de doctorado y Lorenzo en el cuarto. Frente a este panorama, Lorenzo viaja a Bogotá para negociar con la universidad una extensión de tiempo, manifestando su interés en hacer el posdoctorado; en caso de una negativa, solicitaría una licencia no remunerada. En este caso Lorenzo no solicita apoyo económico - a pesar de que lo necesita- solo tiempo, para retornar junto con su esposa e hijos, sin perder su trabajo y que le sean cobradas las deudas adquiridas para sacar adelante su proyecto de cualificación profesional (notas de campo).
}

Estas historias reflejan las complejas relaciones que se tejen entre afectos, dinero y carrera profesional en el marco de las políticas científicas e institucionales que están afrontando las mujeres y sus parejas. Aproximarse a la movilidad académica de larga duración, poniendo el foco en los afectos, implica poner en debate varios asuntos: (1) La ambigüedad de ser proyectos migratorios transitorios con el argumento de ser con fines de cualificación académica pero desconociendo las extensas temporalidades, lo que conlleva una reorganización vital de las personas que los encarnan. (2) La manera de resolver esta ambigüedad ha quedado en el plano de las negociaciones íntimas de las personas, decisiones que están directamente imbricadas con las políticas científicas de gobierno y las políticas institucionales universitarias. (3) Por medio de un intenso trabajo relacional (Zelizer, 2009) las parejas toman decisiones estratégicas para conectar sus proyectos afectivos y profesionales, desobedeciendo vitalmente los perfiles de sujetos "idóneos" que están detrás de las políticas científicas.

\section{Consideraciones finales}

A través de la mirada comparativa de dos grupos diferentes de mujeres cualificadas y dos trayectos geográficos migratorios distintos sur-norte y sur-sur se mostró la importancia de los asuntos afectivos en la migración/movilidad femenina calificada. 
Poner el acento en la transnacionalización de los afectos en tales contextos visibiliza nuevas comprensiones que eran omitidas por los estudios sobre migración y movilidad cualificada y que se corresponden con una dimensión central de la vida de las personas protagonistas de estos movimientos geográficos. En realidad, son miradas analíticas complementarias a las cuestiones de circulación de habilidades y conocimientos y a los asuntos de la economía global. Concretamente dan un espectro mayor y más integral sobre los motivos y estrategias migratorias, las necesidades, dificultades, formas de afrontamiento y marcos de agencia de las mujeres. Adicionalmente, cuestionan los imaginarios sobre la homogeneidad de la migración/movilidad cualificada mostrando las particularidades de los grupos que la conforman y que merecen aproximaciones contextualizadas.

Ahora bien, a partir de circunstancias vitales diferentes que vivencian mujeres colombianas calificadas, unas como migrantes en el norte global y otras en movilidad académica en un país del sur se puede comprender que dentro de las relaciones amorosas y de conyugalidad coinciden las relaciones de intimidad con los asuntos económicos. Visibilizar estas cuestiones les permitió a las primeras adquirir mayores márgenes de actuación, incluso resignificando fuertes imaginarios del amor como "hablar de dinero no es romántico", reconociendo las implicaciones que conlleva para su vida volver a comenzar su carrera laboral y profesional en un país del norte pero generando mecanismos de equilibrio diferenciales por medio de las negociaciones con sus parejas. Cuestionando por un lado, el lugar pasivo o de estigmatización que habitualmente tienen las mujeres latinas en el imaginario social sobre las parejas binacionales sur-norte y por el otro, demostrando cómo estas situaciones están articuladas a las políticas migratorias que restringen tanto la movilidad como el ejercicio profesional de las mujeres entre las fronteras y que son en últimas las que están generando la disyuntiva pareja versus carrera profesional por su condición de ser migrantes del sur global, disyuntiva que en sus países de origen mujeres con estos perfiles no enfrentan.
Las segundas nos muestran como las mujeres sacan adelante sus estudios de postgrado cruzando las fronteras con los suyos tomando decisiones estratégicas que en la vida conyugal implican un gran esfuerzo para intentar crear y sostener las vidas conectadas. Ese esfuerzo permanente se refleja en sus trayectorias de movilidad académica por articular afectos, carrera profesional y sostenimiento económico. Es lo que Zelizer (2009) llama trabajo relacional el cual implica no solo establecer los vínculos, sino su mantenimiento con interacciones afectivas permanentes y exigentes, renegociándolas, dándoles nuevas formas o marcos de referencia e incluso a veces poniéndoles fin. Evidencian que el dinero y las actividades económicas cohabitan regularmente con la intimidad e incluso la sustentan. Adicionalmente, exponen la invisibilidad de los proyectos de movilidad en pareja o familia dentro de las políticas científicas colombianas, descargando en las negociaciones de la intimidad las consecuencias derivadas de tal invisibilidad mostrando la distancia que tiene la política científica con un sector importante de las personas que la protagonizan.

En ambos casos como señala Belén Agrela (2006) es claro que los imaginarios de género y nacionalidad son reproducidos en las políticas sociales y tienen consecuencias concretas en la vida de las mujeres en destino.

En este orden de ideas, el diálogo permanente entre género y transnacionalismo como eje transversal del artículo muestra la forma en que se entrelazan compleja y paradójicamente durante los procesos de movilidad trasnacional femenina calificada factores globales, locales y personales que invitan a un análisis más complejo en las articulaciones de relaciones amorosas, trayectoria laboral o profesional, nacionalidad, capital económico, social y cultural, y movilidad social en las migraciones cualificadas femeninas.

Finalmente, lo interesante de todo esto es ver cómo a través del análisis de aspectos micro como los asuntos de intimidad se evidencian las fragilidades de los escenarios macro de manera cercana a la cotidianidad de las personas. 


\section{Referencias}

Ackers, L. (2004). Managing Relationships in Peripatetic Careers: Scientific Mobility in the European Union. Women's Studies International Forum, 27(3), 188-201.

Agrela, B. (2009). De los significados género e inmigración (re)producidos en las políticas sociales y sus consecuencias para la acción e integración social. En L. Cachón y M. Laparra (Comps.), Inmigración y Políticas Sociales (pp. 239-267). Barcelona, España: Bellaterra.

Bermudez, R. (2014). Trayectorias laborales de migrantes calificadas por razones de estudio. $R v$ Estudios Demográficos y Urbanos, 29(2), 257-299.

Bermudez, R. (2015). La movilidad internacional por razones de estudio: Geografía de un fenómeno global. Migraciones Internacionales, 8(1), 95-125.

Brah, A. (2006). Diferença, diversidade, diferenciação. Cadernos Pagu, 26(1), 329-365.

Constable, N. (2003). Romance on a Global Stage: Pen Pals, Virtual Ethnography, and "Mail Order" Marriages. Berkeley and Los Angeles, US: University of California Press.

Constable, N. (Ed.). (2005). Cross-Border Marriages: Gender and Mobility in Transnational Asia. Philadelphia, US: University of Pennsylvania Press.

Echeverri, M. (2010). "Son diez horas de viaje y cinco años que te meten encima". Proyectos, identidades y vínculos transnacionales de los y las jóvenes colombianas en España (tesis doctoral). Universidad Complutense de Madrid, Madrid, España.

Echeverri, M. (2014). A los dos lados del Atlántico. Reconfiguraciones de los proyectos migratorios y la vida familiar transnacional de la población colombiana en España. Papeles Del CEIC, (2), 1-28. Recuperado de http://www.ehu.eus/ojs/index.php/papelesCEIC/article/view/12988

França, T. y Padilla, B. (2017) Reflecting on International Academic Mobility Through Feminist Lenses: Moving Beyond the Obvious. Comparative Cultural Studies: European and Latin America Perspectives, 2(3), 40-50. Recuperado de http://www.fupress.net/index.php/ccselap/article/ view/20825/20500

Gil, S. y Pedone, C. (2014). Introducción. Familias migrantes y Estados: vínculos entre Europa y América Latina. Papeles del CEIC, 2014/2. http://dx.doi.org/10.1387/pceic.13020

Giorgi, A y Raffini, L. (2015). Love and Ryanair: Academic Researchers' Mobility. Forum Sociológico, (27), 43-52.

Gonzálvez, H. (2010). Migración colombiana, género y parentesco: La organización social de los cuidados (tesis doctoral). Universidad de Granada, Granada, España.

Kofman, E. (2000). The Invisibility of Female Skilled Migrants and Gender Relations in Studies of Skilled Migration in Europe. International Journal of Population Geography, 6(1), 45-59.

Mohanty, C. T. (1984). Under Western Eyes: Feminist Scholarship and Colonial Discourses. Boundary 2, 12(3), 333-358.

Pavajeau, C. (2016). Reseña del Dossier: Mobilidade Científica \& Imigração Qualificada. (Eds.) Beatriz Padilla y Thais França. Forum Sociológico, (27), 1-3. Recuperado de http://www.rimac.mx/ dossier-mobilidade-cientifica-imigracao-qualificada/ 
Migración y movilidad académica de mujeres colombianas cualificadas, transnacionalización de los afectos y asuntos de intimidad

Pavajeau, C. (2017). Escenarios de movilidad académica en pareja: negociando afectos, dinero y carrera profesional en el marco de las políticas científicas en Colombia. En T. França y B. Padilla (Eds.), Transnational Scientific Mobility. Perspectives from the North and the South, (pp. 231-254).

Pedone, C. (2008). Varones aventureros vs. madres que abandonan: reconstrucción de las relaciones familiares a partir de la migración ecuatoriana. REMHU. Revista Interdisciplinar da Mobilidade Humana, XVI(30), 45-64.

Pedone, C. (2011). Familias en movimiento. El abordaje teórico-metodológico del transnacionalismo familiar latinoamericano en el debate académico español. Revista Latinoamericana de Estudios de Familia, 3, 223-244.

Pedone, C., Agrela, B. y Gil, S. (2012). Políticas públicas, migración y familia: una mirada desde el género. Rv PAPERS. Revista de Sociología, 97(3), 541-568. Recuperado de http://papers.uab.cat/ article/view/v97-n3-pedone-agrela-gil

Pedone, C. y Alfaro, Y. (2015). Migración cualificada y políticas públicas en América del Sur : el programa PROMETEO como estudio de caso. Forum Sociológico, (27), 31-42.

Piscitelli, A. (2008). Interseccionalidades, categorias de articulação e experiências de migrantes brasileiras. Sociedade e Cultura, 11(2), 263-274.

Piscitelli, A. (2011). Estereotipos, migración y casamiento: brasileñas en España. En F. J. García y N. Kressova (Coords.), Actas del I Congreso Internacional sobre Migraciones en Andalucía (pp. 22232232). Granada, España: Instituto de Migraciones.

Puyana, Y., Micolta, A. y Palacio, M. C. (Eds.). (2013). Familias colombianas y migración internacional: entre la distancia y la proximidad. Bogotá, Colombia: Universidad Nacional de Colombia.

Puyana, Y., Motoa, J. y Viviel, A. (2009). Entre aquí y allá. Las familias colombianas transnacionales. Bogotá, Colombia: UE, Universidad Nacional de Colombia, Fundación Esperanza.

Riaño, Y.(2007). Migration de femmes latino-américaines qualifiées universitaires en Suisse: Géographies migratoires, motifs de migration et questions de genre. Recuperado de http://www.flacsoandes.edu. ec/agora/migracion-de-mujeres-latinoamericanas-universitarias-suiza-geografias-migratorias

Riaño, Y. (2011). "He's the Swiss Citizen, I'm the Foreign Spouse": Binational Marriages and the Impact of Family-Related Migration Policies on Social Integration and Gender Relations. In A. Kraler, E. Kofman, M. Kohli \& C. Schmol, (Eds.), Gender, Generations, and the Family in International Migration (pp. 265-283). Amsterdam, Netherlands: Amsterdam University Press

Rivas, A. M. y Gonzálvez, H. (2009). Familias transnacionales colombianas. Transformaciones y permanencias en las relaciones familiares y de género. Madrid, España: Cataratas.

Strathern, M. (2006). O gênero da dádiva: problemas com as mulheres e problemas com a sociedade na Melanésia. Campinas, Brasil: UNICAMP.

Zelizer, V. (2009). La negociación de la intimidad. México D. F., México: Fondo de Cultura Económica.

Zelizer, V. (2013). Sobre la negociación de la intimidad. En R. Codero (Ed.), Formas de comprender el presente (pp. 91-104). Santiago, Chile: Ediciones Universidad Diego Portales. 